\title{
THE EFFECT OF DEXAMETHASONE ON PREGNANCY IN THE RABBIT
}

\author{
JUNE Z. KENDALL* AND G. C. LIGGINS \\ Departments of Zoology and Obstetrics \& Gynaecology, \\ University of Auckland, Auckland, New Zealand
}

(Received 26th Fuly 1971, accepted 6th Fanuary 1972)

On Days 13 and 14 of gestation in the rabbit, injections of cortisone acetate interrupt pregnancy by causing resorption of conceptuses (Robson \& Sharaf, 1952). In the later stages of pregnancy, glucocorticoids administered to the mother have a shortening effect on gestation which is independent of a lethal effect on fetuses (Adams \& Wagner, 1969). Large doses of glucocorticoids injected into the mother are known to induce premature delivery in sheep (Fylling, 1971), cows (Adams \& Wagner, 1970) and goats (van Rensburg, 1970). Detailed investigations of the physiological significance of glucocorticoids in the termination of pregnancy in sheep and goats have revealed no consistent change in the plasma levels of maternal corticosteroids with advancing gestation (Paterson \& Harrison, 1967; Thorburn, Nicol, Bassett, Shutt \& Cox, 1972; Paterson \& Linzell, 1971) whereas in the fetuses of both species there is a marked increase in corticosteroid levels immediately before the onset of labour (Thorburn et al., 1972). This fetal corticosteroid has been shown to initiate changes in the plasma levels of maternal hormones (Liggins, Grieves, Kendall \& Knox, 1972; Thorburn et al., 1972); progesterone falls, oestrogen rises and there is an increase in release of prostaglandin $F$ (PGF) from the uterus.

The aim of the present study was to observe the effect on the length of pregnancy in the rabbit of a glucocorticoid administered into either a maternal or a fetal site. Rabbit pregnancies were dated from Day 0 of an observed mating and were divided into three groups. In Group A (twenty-one animals) and Group B (nineteen animals), a laparotomy was performed within 10 days of term. Either dexamethasone phosphate (Group A) or an equivalent volume of normal saline (Group B) was injected into each amniotic sac. Litters of four or less were given a dose of $0.4 \mathrm{mg} / \mathrm{sac}$ and those of more than four were given $0.24 \mathrm{mg} / \mathrm{sac}$; thus, the total dose was always less than $2 \mathrm{mg}$. Does in Group C (thirty-three animals) received a single intramuscular (i.m.) injection of $1 \mathrm{mg}$, $2 \mathrm{mg}$ or $4 \mathrm{mg}$ dexamethasone phosphate. Blood was withdrawn from a marginal ear vein of two rabbits. Samples were taken on the day before operation and daily until delivery. Plasma progestins were assayed by a competitive proteinbinding method (Liggins et al., 1972). In two additional animals, one treated with dexamethasone phosphate by the intra-amniotic (i.a.) route on Day 25

* Present address: Department of Obstetrics \& Gynaecology, University of Auckland, Auckland 3, New Zealand. 


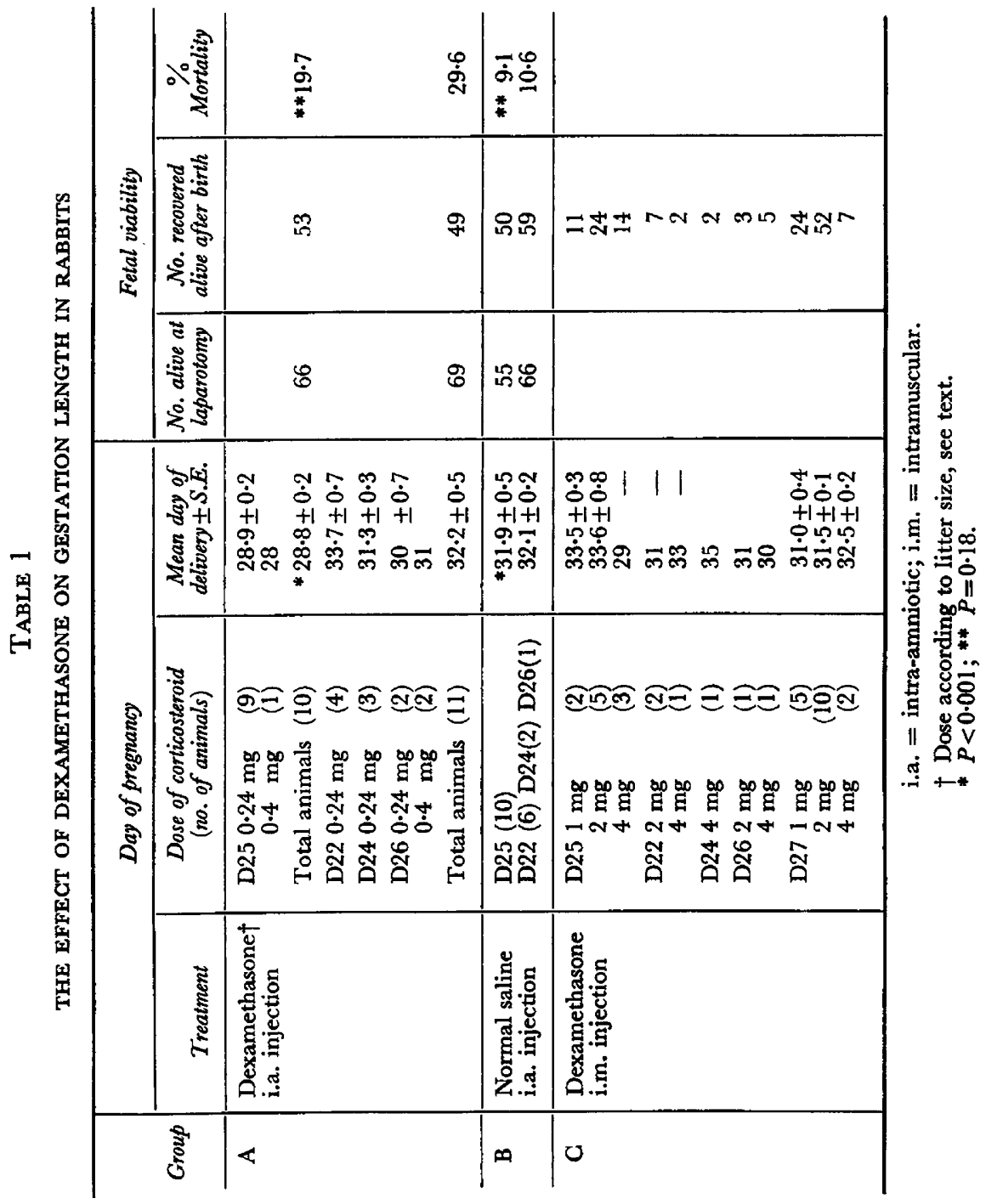


and the other a control doe at the same stage of gestation, the sensitivity of the uterus to a daily i.m. injection of 1 i.u. oxytocin was determined. Intrauterine pressure was recorded by means of a $0 \cdot 2-\mathrm{ml}$ balloon catheter connected to a Statham transducer (Model P23D6) and a Sanborn Twin Viso recorder. The catheter was inserted between the chorion and the uterine wall of a cervical sac and was retained within the uterus until delivery.

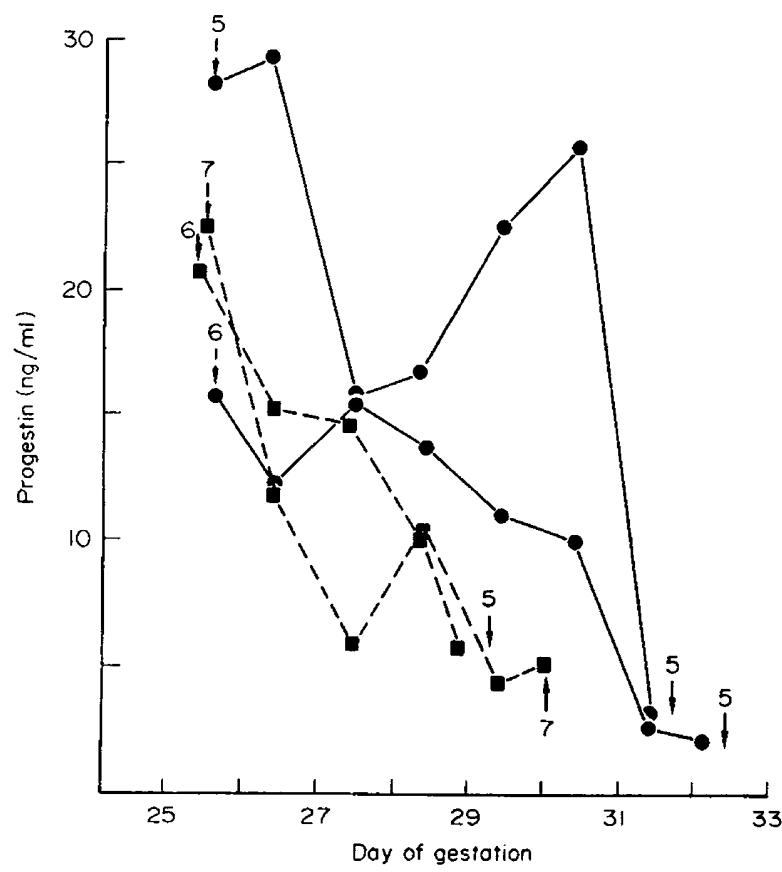

TEXT-FIG. 1. The concentration of progestin in peripheral plasma measured from Day 25 to delivery in two control (0) and two dexamethasone-treated ( $(\mathbf{0})$ does. $\downarrow$, No. of live fetuses at laparotomy; $\downarrow$, no. of live fetuses at delivery.

From Table 1, it may be seen that animals injected with dexamethasone by the i.a. route on Day 25 produced their litters 3.1 days earlier than control animals treated with normal saline on the same day $(P<0.001)$. Dexamethasone was without effect before or after Day 25 . An i.m. injection of $4 \mathrm{mg}$ dexamethasone into the doe on Day 25 reduced the length of pregnancy by 2.9 days, but was ineffective when given at other stages of gestation. The fetal mortality in rabbits treated with i.a. dexamethasone on Day 25 did not differ from that of the control group $(P=0 \cdot 18)$. The plasma concentration of progestins declined to low levels before delivery (Text-fig. 1). The fall in progestin concentration was associated with increased uterine sensitivity to oxytocin. On Day 27, the uterus of the treated animal responded $1 \mathrm{~min}$ after the injection of oxytocin with frequent, low amplitude $(15 \mathrm{~mm} \mathrm{Hg}$ ) contractions. On Day 28, high intensity uterine activity resulted in the delivery of the first fetus 8 min after injection. Oxytocin had no effect on spontaneous intrauterine pressure when administered on Day 27 or 28 to the control doe. 
The results show that premature parturition can be induced in the rabbit by dexamethasone administered i.m. to the doe or by the i.a. route on Day 25 of pregnancy. When injected into the fetal compartment, the effective dose was less than half that required by the i.m. route. As the difference in effective doses may represent a difference in the mode of absorption from two sites, the primary site of action of the glucocorticoid remains undetermined. If a glucocorticoid has a physiological rôle in the onset of labour in the rabbit one would expect to find an increase in corticosteroids in either the fetus or the doe close to term. Westphal (1970) recorded no change in the maternal plasma levels of corticosteroids in samples taken from rabbits up to Day 28 of pregnancy. On the other hand, within the fetal compartment two developmental features known to be stimulated by glucocorticoids - the accumulation of liver glycogen (Jost \& Picon, 1970) and pulmonary surfactant (Kotas \& Avery, 1971) - have a time-course in the fetal rabbit which suggests that there may be an increase in adrenocortical activity at about Day 26 to Day 28 of gestation.

The declining levels of plasma progestins before premature delivery indicate the occurrence of premature luteolysis. The mechanism by which i.a. injection of a glucocorticoid may induce luteolysis and premature parturition is unknown. In the ewe, the goat and the guinea-pig, it has been shown that luteolysis is accompanied by a release of PGF from the uterus. Furthermore, PGF $2 \alpha$ causes rapid luteal regression when injected into hysterectomized, pseudopregnant rabbits (Scott \& Rennie, 1970). In the pregnant ewe (Liggins \& Grieves, 1971) and the pregnant goat (Thorburn et al., 1972), the release of PGF can be stimulated by the infusion of dexamethasone into the fetus. Dexamethasone may induce luteolysis in the pregnant rabbit by releasing $\mathrm{PGF}_{2 \alpha}$, but it is unlikely that $\mathrm{PGF}_{2 \alpha}$ is the oxytocic factor which initiates labour in the rabbit. Although prostaglandins have been shown to stimulate uterine activity in the human (Embrey, 1970), the monkey (Kirton, Pharriss \& Forbes, 1970) and the ewe (Liggins, unpublished data), Porter \& Behrman (1971) have recently demonstrated that the non-pregnant rabbit uterus in vivo can be stimulated only when $\mathrm{PGF}_{2 \alpha}$ is injected intravenously in large doses. In preliminary experiments in our laboratory, intra-aortic infusions of $\mathrm{PGF}_{2 \alpha}$ at rates up to $2 \mu \mathrm{g} / \mathrm{min}$ failed to stimulate uterine activity in lightly anaesthetized pregnant rabbits near term.

We thank Mrs G. Morton and Mrs I. Muller for their skilled technical assistance. This work has been assisted by a grant from the Wellcome Trust.

\section{REFERENCES}

Adams, W. M. \& WAGner, W. C. (1969) The elective induction of parturition in cattle and sheep and rabbits. (Abstract). AVMA meeting, Minneapolis. 7. Am. vet. med. Ass. 154, 1397.

Adams, W. M. \& Wagner, W. C. (1970) The role of corticoids in parturition. Biol. Reprod. 3, 223.

EMBREY, M. P. (1970) Induction of abortion by prostaglandins $\mathrm{E}_{1}$ and $\mathrm{E}_{2}$. Br. med. F. iii, 196.

Fylling, P. (1971) Premature parturition following dexamethasone administration to pregnant ewes. Acta endocr., Copenh. 66, 289.

Jost, A. \& Picon, L. (1970) Hormonal control of fetal development and metabolism. Adv. metab. Disorders, 4, 123.

Kirton, K. T., Pharriss, B. B. \& Forbes, A. D. (1970) Some effects of prostaglandins $E_{2}$ and $F_{2 a}$ on the pregnant rhesus monkey. Biol. Reprod. 3, 163. 
Kotas, R. V. \& Avery, M. E. (1971) Accelerated appearance of pulmonary surfactant in the fetal rabbit. F. appl. Physiol. 30, 358.

Liggins, G. C. \& Grieves, S. A. (1971) Possible role for prostaglandin $F_{2 a}$ in parturition in sheep. Nature, Lond. 232, 629.

Liggins, G. C., Grieves, S. A., Kendall, J. Z. \& Knox, B. S. (1972) The physiological rôles of progesterone, oestradiol-17 $\beta$ and prostaglandin $\mathrm{F}_{2 \alpha}$ in the control of ovine parturition. $\mathcal{F}$. Reprod. Fert. Suppl. 16, 85.

Paterson, J. Y. F. \& Harrison, F. A. (1967) The specific activity of plasma cortisol in sheep during continuous infusion of cortisol-1,2- $\mathrm{H}^{3}$, and its relation to the rate of cortisol secretion. $\mathcal{J}$. Endocr. 37, 269.

Paterson, J. Y. F. \& Linzell, S. L. (1971) The secretion of cortisol and its mammary uptake in the goat. F. Endocr. 50, 493.

Porter, D. G. \& Behrman, H. R. (1971) Prostaglandin-induced myometrial activity inhibited by progesterone. Nature, Lond. 232, 627.

Robson, J. M. \& Sharaf, A. A. (1952) Effect of adrenocorticotrophic hormone (ACTH) and cortisone on pregnancy. F. Physiol., Lond. 116, 236.

Scott, R. S. \& Rennie P. I. C. (1970) Factors controlling the life-span of the corpora lutea in the pseudo-pregnant rabbit. F. Reprod. Fert. 23, 415.

Thorburn, G. D., Nicol, D. H., Bassett, J. M., Shutr, D. A. \& Cox, R. I. (1972) Parturition in the goat and sheep: changes in corticosteroids, progesterone, oestrogens and prostaglandin $F$. $\mathcal{F}$. Reprod. Fert. Suppl. 16, 61.

van Rensburg, S. J. (1970) The termination of gestation. Proc. S. Afr. Soc. Anim. Prod. 9, 17.

WestPhAL, U. (1970) Corticosteroid-binding globulin and other steroid hormone carriers in the blood stream. F. Reprod. Fert. Suppl. 10, 15. 